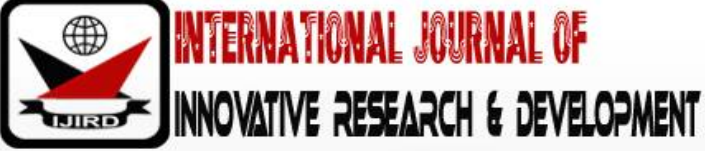

ISSN 2278 - 0211 (Online)

\section{Thermal Kinetics and Post Curing Thermal Stability of Bio- Based Phenol Formaldehyde Resins for Its Potential in Particleboard Production}

Olayiwola Yetunde Bolarinwa
Lecturer, Department of Wood and Paper Technology,
Federal College of Forestry, Jericho, Ibadan, Nigeria
Oladiran Fasina
Professor, Department of Biosystems Engineering,
Auburn University, Alabama, USA
Ogunleye Bolade Mercy
Senior Lecture, Department of Wood and paper Technology,
Federal College of Forestry Jericho, Ibadan, Nigeria

\begin{abstract}
The thermal degradation kinetics and post curing behavior of phenol-formaldehyde and Bio-phenol formaldehyde (BPF) resole resins were investigated with thermogravimetry analysis at four different heating rates $\left(5,10,15\right.$ and $\left.20^{\circ} \mathrm{C} / \mathrm{min}\right)$ from 25 to $700^{\circ} \mathrm{C}$. The curing reaction for all the resole resins proved to be approximately 1 st order, and the activation energies of the BPF resins at $25 \mathrm{wt} \%$ and $50 \mathrm{wt} \%$ bio-phenol replacements were $132.2 \mathrm{~kJ} / \mathrm{mol}$ and $131.6 \mathrm{~kJ} / \mathrm{mol}$. These were comparable to that of the laboratory synthesized pure PF resin $131.0 \mathrm{~kJ} / \mathrm{mol}$ but also remarkably lower than the commercial PF resin $(138.1 \mathrm{~kJ} / \mathrm{mol})$ respectively. The result of the thermal degradation kinetics showed that the post-curing thermal stability of the 25 and $50 \mathrm{wt} \% \mathrm{BPF}$ resins were similar to that of the commercial and laboratory synthesized pure $\mathrm{PF}$ resin but, that of $75 \mathrm{wt} \%$ differed from the commercial or laboratory synthesized PF resin.
\end{abstract}

Keywords: Thermogravimetric analysis (TGA), curing kinetics, Activation energy, phenol-formaldehyde resole resin, BioPhenol Formaldehyde resol resin (BPF)

\section{Introduction}

Phenol, being the most costly chemical raw material for the manufacturing of Phenol Formaldehyde PF resins, a thermosetting resins classified as exterior adhesive because of its resistance to water, weathering, and high temperature in the cured glue line Dwindling of petroleum resources as well as increasing demands for petroleum by developing economies, political and environmental concerns over fossil-based resources has necessitated the interest in exploring and developing alternative renewable resources for both energy and chemical production. (Russel, et al., 1985). The lignocellulosic biomass used for the production of bio-phenol precursor is Detarium senegalense which is composed of lignin, an amorphous micromolecule comprising of three phenyl-propanols i.e., phydroxyl-phenyl propanol, guaiacyl-propanol and syringyl-propanol, linked together by condensed linkages and ether linkages. This macromolecule can be decomposed/ de-graded into the oligomeric and monomeric phenolic compounds through thermochemical technology such as direct liquefaction (Kleinert, etal., 2009; Wang. et al., 2009). In this regard, lignocellulosic biomass can be a potential source of bio-phenolic compounds to replace petroleumbased phenol in the production of PF resins.

D. senegalense isa lesser-utilized tropical hardwood species in Nigeria and among the properties that will qualify bark of wood as a potential raw material in the developing bio refinery and chemical industries are the percentage of the bark they contain and the extent of within and between species variation in bark percentages. Ten (10) tropical hard wood species was studied for variation in their barks percentages within trees of the same species and those of different species, D. senegalense performed best (Ogunwusi, 2013).

Thermosetting adhesives are usually monitored by exothermic or endothermic behaviour during gelling and hardening Modifications of PF resins with renewable phenol from barks and other additives to improving the reactivity of $\mathrm{PF}$ reins has necessitated studying the post curing thermal stability of PF resin at higher temperature. Thermal analysis and testing of polymers and lifecycle is a powerful means of measuring physical properties, transitions, ageing processes, the effect of additives and the influence of diverse production conditions on materials. 
It is essential that the properties of polymers, raw materials and finished products are well understood as they are integral to enhancing the performance of materials to meet specifications for the desired end-use, and within the remit of product failure analysis

Thermal analysis is therefore, a powerful technique for studying the kinetics in relations to the physicochemical processes. Thermogravimetric analysis TGA is a technique in which the mass of a substance is measured as a function of temperature while the substance is subjected to a controlled temperature programme. In this definition, a controlled temperature program means heating or cooling the sample at some predetermined and defined rate. TGA is a common technique for characterizing polymer thermal degradation behavior (Shulman 1996 and Chetan et al., 1997). Kinetic studies during the thermal degradation process have been used to acquire fundamental understanding of the structural changes in phenolic resins (Chen et al., 2008). Depending on whether a single or multiple-heating rate is used, the technique used to obtain the kinetic parameters is differential or an integral method (Popescu 1996; Vyazovkin et al., 2011). Multiple heating rates method gives more reliable results than the single heating rate method with smaller experimental errors (Cetic and Ozmen 2002). "Modelfree" isoconversional method is a widely adopted technique for deriving relevant kinetic parameters using thermogravimetric (TG) and Differential Thermogravimetric (DTG) curves measured at different heating rates of mass change per-pre-selected temperature interval that makes no presumption about the reaction function and reaction order (Vyazovkin 2001; Orfao 2002; Vyazovkin et al., 2011). Thermogravimetric data can be presented in two ways. The TG curve is a plot of the mass against time or temperature, with the mass loss on the ordinate plotted downward and mass gains plotted upward relative to a baseline. Alternatively, data can be presented as a Derivative Thermogravimetric (DTG) curve, which is a plot of the rate of change of mass (m) with respect to time (t) or temperature (T) against time or temperature. (Rao et al., 1998; Lee et al., 2003).

Ability to analyze the structure and network formation of these resins with modern instrumental techniques increases our understanding of these phenomena transitions, ageing processes, the effect of additives and the influence of diverse production conditions on materials there by allows for better product quality control.

\section{Experimental}

\subsection{Synthesis of BPF Resole Resins Using the Phenol Bark Component of Detarium Senegalense Bark}

Bio-phenol formaldehyde resole resin was synthesized using bark phenolic compound from D. senegalense (forest biomass) via the solvolysis liquefaction method, the bio-oil obtained, was successfully incorporated into the synthesis of bio-phenol formaldehyde (BPF) resins up to 75 percent replacement by weight substitution for petroleum-based phenol.

The resin synthesis were carried out in a laboratory glass reactor equipped with a stirrer, a thermometer, and a reflux condenser. The mixture of phenol and $37 \%$ aqueous formaldehyde was heated up to a temperature of $45^{\circ} \mathrm{C}$, and then the catalyst, a $10 \%$ sodium hydroxide solution as was added. After the components were heated to $90^{\circ} \mathrm{C}$ over a period of $30 \mathrm{~min}$, the temperature was kept at $90^{\circ} \mathrm{C}$ for $60 \mathrm{~min}$. The experiment was repeated for $25 \%$, $50 \%$ and $75 \%$ phenol replacement.

\subsection{Commercial PF Resins}

In order to understand how the bark phenolic compounds affect the resulting resin properties, a conventional commercial pure phenol formaldehyde is used as control for the study.

\subsection{Curing Characterization:}

The thermal curing properties of the resins were evaluated with a Differential Scanning Calorimetry TA DSCQ200, TA Instruments, Auburn University, Alabama. USA) under (50-60) $\mathrm{ml} / \mathrm{min} \mathrm{N}_{2}$ at four different heating rates $\left(5,10,15\right.$ and $\left.20^{\circ} \mathrm{C} / \mathrm{min}\right)$ between $120^{\circ} \mathrm{C}$ and $200^{\circ} \mathrm{C}$ in a sealed Aluminum crucible

\subsection{Post Curing Thermal Stability of the PF Resins Using Thermal Gravimetricanalyzer (TGA)}

The phenol formaldehyde resins and the bio-based phenol formaldehyde resins, that were previously cured in an oven at $80^{\circ} \mathrm{C}$ for 24 hours using DSC technique. The cured resins were ground into fine powders that were able to pass through a 100 mesh screen. About $10 \mathrm{mg}$ of each cured resin sample was placed on a platinum pan and heated from $25{ }^{\circ} \mathrm{C}$ to $700{ }^{\circ} \mathrm{C}$ at the rate of $10{ }^{\circ} \mathrm{C} /$ min under $\mathrm{N}_{2}$ atmosphere using a thermal gravimetric analyzer (TGA-Q500, TA Instruments, Auburn University; Al. USA). For the removal of moisture from the resins, they were mounted in a vacuum-dried oven at $40^{\circ} \mathrm{C}$ for $48 \mathrm{~h}$.

\subsection{Curing Kinetics Mechanisms for the PF and BPF Resins}

The non-isothermal DSC methods have been widely used for investigating the curing kinetics of thermosetting phenolic resins (Park et al., 1999; Want et al., 2005; Gabilondo et al., 2007; Wang et al., 2009; Cheng et al., 2011; Zhao et al., 2011; and Homaira, Siddiqui, 2013). The results from a single heating rate of (10 $\mathrm{\circ} / \mathrm{min}) \mathrm{may}$ be inconsistent (Park et al., 1999; and Vázquez et al., 2002). The multiple-heating rate method was employed with four different heating rates varying between $5 \circ \mathrm{C} / \mathrm{min}$ and $20^{\circ} \mathrm{C} / \mathrm{min}$ (Table 2). By assuming that the cure reaction 
pathway does not change with the heating rate, the curing kinetic parameters of the curing reaction of the resins were calculated using Kissinger equation. (Kissinger, 1957). The equation written as:

$\operatorname{In}\left(\frac{\beta}{F}\right)=\operatorname{In} \frac{A K}{\mathbb{E}_{G}}+\frac{1}{I}\left(\frac{E_{a}}{k}\right)$

Where, $\mathrm{T}_{\mathrm{p}}$ is the maximum exothermic temperature in the DSC profile, Ea is the activation energy (kJ/ mol), and Ris the gas constant $(=8.314 \mathrm{~J} / \mathrm{mol} / \mathrm{K})$. The activation energy (Ea) and reaction order $(\mathrm{n})$ was calculated from the slope of the regression line of plots of $\ln \left(\beta / \mathrm{T}_{\mathrm{p}}{ }^{2}\right)$ vs. $1 / \mathrm{T}_{\mathrm{p}}$, respectively. The working plots are shown in Figure 2 , and the calculated results presented in Table 3 . The curing reaction for all the resole resins is approximately 1 st order $(\mathrm{n}=$ 0.94 0.95)

\subsection{Kinetic Analysis of the PF Resins and Bio-Based PF Resins Thermal Degradation Process Using Kissinger Equation}

The nth-order and autocatalytic kinetics are the two reaction mechanisms used to describe curing reactions.

They can be expressed as follows. For nth order kinetics,

The rate of the solid-state reaction is given by

$$
\frac{\mathrm{d} \alpha}{\mathrm{dt}}=\mathrm{kf}(\alpha)
$$

$\mathrm{K}$ is the rate constant $\alpha-$ it is the fraction of reaction, or extent of reaction, $\mathrm{f}(\alpha)$ is the differential form of the reaction model.

The extent of reaction is determined by

$$
\alpha=\frac{m u_{i}-r n_{t}}{m_{1}-m_{F}}
$$

Where:

$\mathrm{m}_{\mathrm{i}}$ is the initial mass of the reaction.

$\mathrm{m}_{\mathrm{t}}$ is the mass at time $\mathrm{t}$.

$m_{\mathrm{f}}$ is the final mass at the end of the reaction.

The rate constant $\mathrm{k}$, largely depends on temperature and it is the most important parameter as is directly related to activation energy and pre-exponential factor by the Arrhenius Equation which is as follows:

$\mathrm{K}=\mathrm{Ae}-\mathrm{E} \alpha / \mathrm{RT}$

$\mathrm{E} \alpha$ is the activation energy, $\mathrm{A}$ is the pre-exponential factor, $\mathrm{T}$ is the absolute Temperature and $\mathrm{R}$ is the gas constant. By rearranging and integrating equation (3)

We obtain

$$
\mathrm{g}(\alpha)=\mathrm{k} / \mathrm{t}
$$

where $g(\alpha)$ is the integral form of the kinetic model and t is the time.

From equation (3) and (4)

$$
\mathrm{g}(\alpha)=\mathrm{Ae}(-\mathrm{E} \alpha / \mathrm{RT}) / \mathrm{t}
$$

Taking logarithm and rearranging the terms, the following equation is obtained:

$$
-\ln (\mathrm{t})=\ln (\mathrm{A})-\ln (\mathrm{g}(\alpha))-\frac{\mathrm{E} \boldsymbol{\alpha}}{\mathrm{RT}}
$$

Since the value of $\ln (g(\alpha)$ is very small as compared to $\ln (A)$, it can be neglected and the value of $E \alpha$ and $A$ can be obtained from the plot of $-\ln (\mathrm{t})$ against $1 / \mathrm{T}$.

The value of $\mathrm{E} \alpha$ and $\mathrm{A}$ as obtained will be corresponding to the specific value of $\alpha$ and the time related to that $\alpha$ value.

In solid state decomposition reaction, the rate of reaction, using Equations (3) and (4) can be written in the following form:

$$
\frac{\mathrm{d} \alpha}{\mathrm{dt}}=\mathrm{Ae}^{-\mathrm{E \alpha} / \mathrm{RT}} \mathrm{f}(\alpha)
$$

The Kissinger method is based on the study of the rate equation at the maximum reaction rate in non-isothermal system. At the maximum reaction rate, $\mathrm{d}^{2} \alpha / \mathrm{dt}^{2}$ is equal to zero and thus the following is obtained:

$$
\frac{\mathrm{d}^{2} \alpha}{\mathrm{dt}^{2}}=\left(\frac{E_{\alpha \beta} \beta}{\mathrm{RT}_{\mathrm{m}}^{2}}+\mathrm{Af}^{\prime} \quad(\alpha \mathrm{m}) \mathrm{e}^{-E_{\alpha} / R \mathrm{R}_{\mathrm{m}}}\right)\left(\begin{array}{l}
\mathrm{d} d \mathrm{~g} \\
\mathrm{dt}
\end{array}\right) \mathrm{m}=0
$$

This can be re-written as:

$\mathrm{d}(\mathrm{d} \alpha / \mathrm{dt}) \mathrm{dt}=\mathrm{A} \exp (-\mathrm{Ea} / \mathrm{R} / \mathrm{T})\left(\mathrm{E} \alpha / \mathrm{R} / \mathrm{T}^{2}\right)(1-\alpha)^{\mathrm{n}} \mathrm{dT} / \mathrm{dt}-\mathrm{n}(1-\alpha)^{(\mathrm{n}-1)} \mathrm{A} \exp$

$(-\mathrm{Ea} / \mathrm{R} / \mathrm{T}) \mathrm{d} \alpha / \mathrm{dt}$

By further assuming $n(1-\alpha)(n-1)=0$

a number close to unit, and $\mathrm{dT} / \mathrm{dt}=\beta$ (heating rate) is a constant. Kissinger reached $\mathrm{T}_{\mathrm{m}}$ is the temperature at which the maximum reaction rate is observed, and $\alpha \mathrm{m}$ is the fraction reached at the maximum reaction rate. Taking logarithm and re-arranging, $\beta$

$$
\ln \left(\beta / T_{\mathrm{m}}^{2}\right)=\ln \left(\frac{-\mathrm{AR}}{\mathrm{Ea}} \mathrm{f}^{1}(\alpha \mathrm{m})\right)-\frac{\mathrm{Ea}}{\mathrm{RT}_{\mathrm{m}}}
$$


For the first-order reaction $\mathrm{f}^{1}(\alpha)=-1$ and Eq. 9 becomes

$$
\ln \left(\beta / T_{m}^{2}\right)=\ln \left(\frac{A R}{E a}\right)-\frac{E a}{R T_{m}}
$$

\section{Results and Discussion}

The Kissinger plot thus says that for a given DSC curve with the heating rate, $\beta$, one observes the maximum reaction rate at the peak temperature $\mathrm{T}_{\mathrm{m}}$ : for a set of DSC Curves with different heating rates, one can plot the quantity of $\ln \left(\beta / \mathrm{T}_{\mathrm{m}}^{2}\right)$ against $1 / \mathrm{T}_{\mathrm{m}}$ to obtain the Kissinger plot. From the slope of the Kissinger plot, the Activation Energy Ea is obtained; also, from the intercept, one obtains the pre-exponential factor A as well.

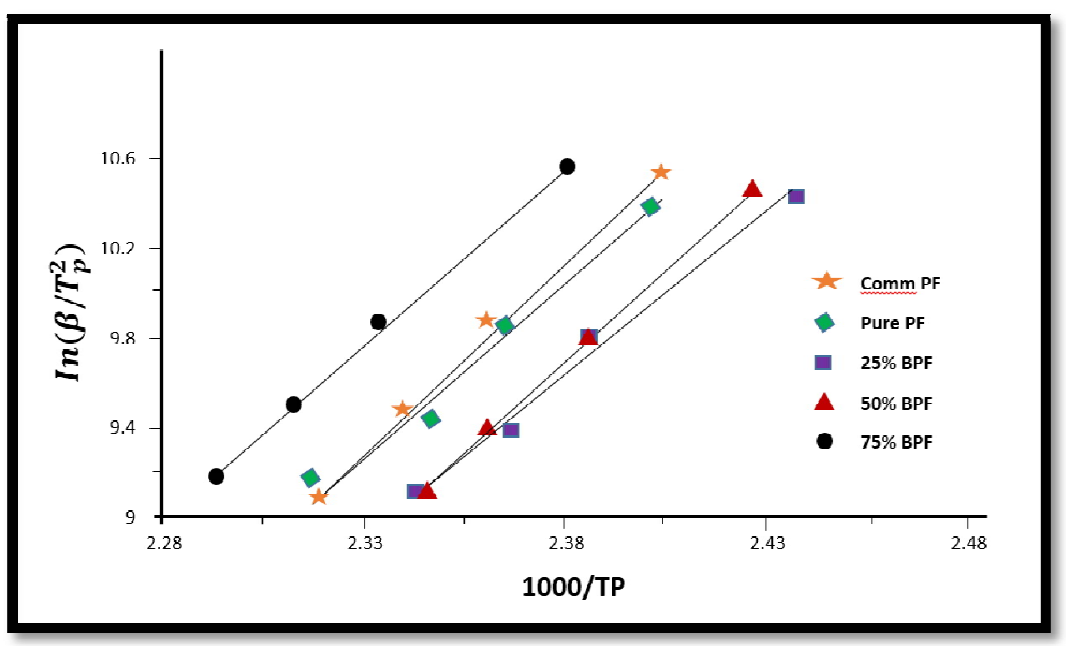

Figure 1: Curing Kinetic Parameters for the Resins as Calculated by the Kissinger Equation (Kissinger, 1957)

\subsection{Thermal Stability Characterization of PF and BPF Resins}

The thermal stability of the non-volatile contents of the BPF and PF resole resins were evaluated by TGA technique. Figure 2 shows the TG-DTG results of the resole resins between $25^{\circ} \mathrm{C}$ and $700{ }^{\circ} \mathrm{C}$. The decomposition temperatures and mass loss values of the thermal events, and mass residue at $700{ }^{\circ} \mathrm{C}$ are listed in Table 1. As shown in Figure 2, all the PF resins present similar thermal decomposition patterns, showing three major thermal event. From the table, the first thermal event for the commercial PF resin was observed at temperature range between 70 and $300 \stackrel{\circ}{\circ}$, and $7 \%$ mass loss was recorded. The second thermal event was observed at temperature range between 365 and $500{ }^{\circ} \mathrm{C}$, and a $7 \%$ mass loss was recorded. The last thermal event was detected at temperature range between 500 and $650{ }^{\circ} \mathrm{C}$ and the overall mass loss of $12 \%$ was obtained. Also, for the laboratory synthesized pure $\mathrm{PF}$ resin, the first thermal event was observed at temperature range between 71 and $300{ }^{\circ} \mathrm{C}$, and $8 \%$ mass loss was recorded. The second thermal event was obtained at temperature range between 305 and $500 \stackrel{\circ}{ } \mathrm{C}$ with a mass loss of $5 \%$. The last thermal event was detected at temperature range between 500 and $649{ }^{\circ} \mathrm{C}$ and the overall mass loss of $11 \%$ was obtained. With 25wt\% BPF resin, three decomposition events also took place. The first event ranges between 150 and $300^{\circ}$ C leading to $5 \%$ mass loss. The second event ranges between 300 and $460{ }^{\circ} \mathrm{C}$, leading to $8 \%$ mass loss; and the third event ranges between 460 and $650 \stackrel{\circ}{\circ}$ leading to the overall mass loss of $15 \%$.For the 50 wt\% BPF resin, three decomposition events were also recorded. The first event ranges between 150 and $300 \stackrel{\circ}{\circ}$ leading to $6 \%$ mass loss, the second event ranges between 300 and $430{ }^{\circ} \mathrm{C}$ leading to $9 \%$ mass loss; and the third event ranges between 430 and $650 \stackrel{\circ}{\circ}$ leading to the overall mass loss of $18 \%$.

However, $75 \mathrm{wt} \%$ BPF, degradation processes occurred at higher temperatures, i.e.; the first thermal event was observed between 150 and $300{ }^{\circ} \mathrm{C}$, leading to $7 \%$ mass loss, the second thermal event, between 300 and $600{ }^{\circ} \mathrm{C}$ leading to the main loss region, (41\% mass loss) and the third event was obtained, between 600 and $690{ }^{\circ} \mathrm{Cleading}$ to $9 \%$ mass loss. Also, from Table 4, the residual carbon contents at $700{ }^{\circ} \mathrm{C}$ were $73,71,68,65$ and $42 \%$ for the commercial PF resin; laboratory synthesized pure PF resin, $25 \mathrm{wt} \% \mathrm{BPF}, 50 \mathrm{wt} \% \mathrm{BPF}$ and $75 \mathrm{wt} \%$ BPF resins, respectively. 


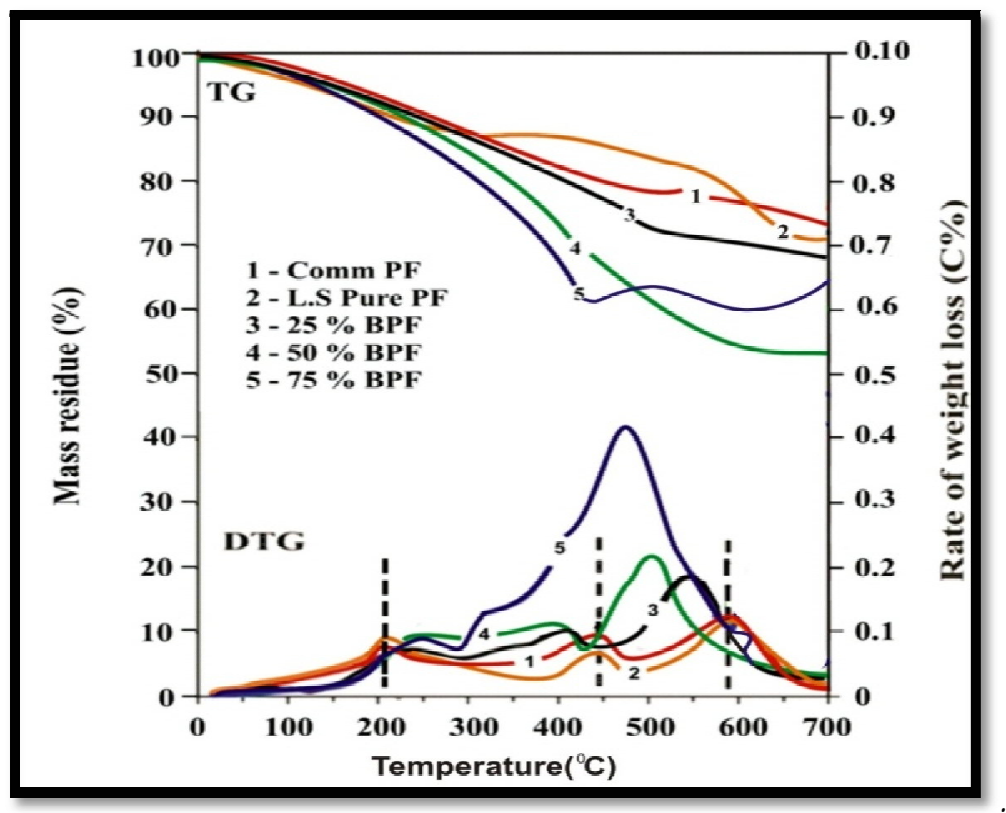

Figure 2: Thermogravimetric (TG) and Derivative Thermogravimetric (DTG) profiles of the resins

It is known that the degradation of phenolic resins has three steps: post-curing, thermal reforming and ring stripping (Khan and Ashraf, 2007; Cheng, 2011). From Figure 2, The first event of the commercial PF resin was observed in the range of $70{ }^{\circ} \mathrm{C}$ to $300{ }^{\circ} \mathrm{C}$ ( $7 \%$ mass loss), which could be ascribed to the post-curing reactions of the resin (the removal of terminal groups and further crosslinking or condensation reactions); the second event was obtained from $365{ }^{\circ} \mathrm{C}$ to $500{ }^{\circ} \mathrm{C}$ ( $7 \%$ mass loss), which could be attributed to the breaking down of the bridged methylene linkage; and the last event was detected in the range of $500{ }^{\circ} \mathrm{C}$ to $650{ }^{\circ} \mathrm{C}$ (the main mass loss region, 12 $\%$ mass loss) due to the breakdown of the ring network. Also for the laboratory synthesized pure PF resin, the first event was observed in the range of $150{ }^{\circ} \mathrm{C}$ to $300{ }^{\circ} \mathrm{C}$ ( $8 \%$ mass loss), which could be ascribed to the post-curing reactions of the resin (the removal of terminal groups and further crosslinking or condensation reactions); the second event was obtained from $365 \stackrel{\circ}{\circ} \mathrm{C}$ to $500 \stackrel{\circ}{\circ}$ ( $5 \%$ mass loss), which could be attributed to the breaking down of the bridged methylene linkage; and the last event was detected in the range of $500{ }^{\circ} \mathrm{C}$ to $650 \stackrel{\circ}{ } \mathrm{C}$ (the main mass loss region, $11 \%$ mass loss) due to the breakdown of the ring

\begin{tabular}{|c|c|c|c|c|}
\hline Resin & $T_{s 1} / T_{p 1} / T_{e 1}\left({ }^{0} C\right)$ & $\mathrm{T}_{\mathrm{s} 2} / \mathrm{T}_{\mathrm{p} 2} / \mathrm{T}_{\mathrm{e} 2}\left({ }^{0} \mathrm{C}\right)$ & $\begin{array}{c}\mathbf{T}_{\mathrm{s} 3} / \mathrm{T}_{\mathrm{p} 3} / \mathrm{T}_{\mathrm{e} 3} \\
\left({ }^{0} \mathrm{C}\right)\end{array}$ & $\begin{array}{c}\text { Mass Residue at } 700 \text { 0C } \\
(\%)\end{array}$ \\
\hline & & $\begin{array}{l}\text { Mass loss in } \\
\text { parentisis }\end{array}$ & & \\
\hline Comm PF & $\begin{array}{c}70 / 219 / 300 \\
(7 \%)\end{array}$ & $\begin{array}{c}365 / 448 / 500 \\
(7 \%)\end{array}$ & $\begin{array}{c}500 / 592 / 650 \\
(12 \%)\end{array}$ & $73( \pm 0.1)$ \\
\hline Lab PF & $\begin{array}{c}71 / 220 / 300 \\
(8 \%)\end{array}$ & $\begin{array}{c}305 / 447 / 500 \\
(5 \%)\end{array}$ & $\begin{array}{c}500 / 593 / 649 \\
(11 \%)\end{array}$ & $71( \pm 0.5)$ \\
\hline $25 \mathrm{wt} \% \mathrm{BPF}$ & $\begin{array}{c}150 / 220 / 300 \\
(5 \%)\end{array}$ & $\begin{array}{c}300 / 422 / 460 \\
(8 \%)\end{array}$ & $\begin{array}{c}460 / 551 / 650 \\
(15 \%)\end{array}$ & $67( \pm 0.4)$ \\
\hline $50 \mathrm{wt} \% \mathrm{BPF}$ & $\begin{array}{c}150 / 242 / 300 \\
(6 \%)\end{array}$ & $\begin{array}{c}300 / 390 / 430 \\
(9 \%)\end{array}$ & $\begin{array}{c}430 / 500 / 650 \\
(18 \%)\end{array}$ & $65( \pm 0.2)$ \\
\hline 75 wt $\%$ BPF & $\begin{array}{c}150 / 242 / 300 \\
(7 \%)\end{array}$ & $\begin{array}{c}300 / 463 / 600 \\
(41 \%)\end{array}$ & $\begin{array}{c}\text { 600/648/ } 690 \\
(9 \%)\end{array}$ & $42( \pm 0.2)$ \\
\hline
\end{tabular}

Table 1: Thermal Stability Characterization of Resins Showing the Decomposition

Temperatures and Mass Loss Values of the Thermal Events, and Mass Residue at $700{ }^{\circ} \mathrm{C}$ for the Resins

When the bio-oil substitution in the BPF resole resins was $50 \mathrm{wt} \%$ and lower, that is $25 \% \mathrm{wt}$, the three decomposition ranges were $150{ }^{\circ} \mathrm{C}$ to $300{ }^{\circ} \mathrm{C}$ (around $5 \%$ mass loss), $300{ }^{\circ} \mathrm{C}$ to $460{ }^{\circ} \mathrm{C}$ ( $9 \%$ mass loss), and $460{ }^{\circ} \mathrm{C}$ to $650^{\circ} \mathrm{C}$ (the main mass loss region, i.e. $15 \%$ mass loss for the $25 \% \mathrm{BPF}$, and $18 \%$ mass loss for the $50 \% \mathrm{BPF}$ ). The ranges of the thermal events for $75 \% \mathrm{BPF}$, however, were transferred to higher temperatures, i.e., $150{ }^{\circ} \mathrm{C}$ to $300{ }^{\circ} \mathrm{C}$ ( $7 \%$ mass loss), $300{ }^{\circ} \mathrm{C}$ to $600 \stackrel{\circ}{\circ} \mathrm{C}$ (the main loss region, $41 \%$ mass loss) and $600{ }^{\circ} \mathrm{C}$ to $690{ }^{\circ} \mathrm{C}$ (9\% mass loss). As discussed previously in the DSC analysis, substituting phenol with bio-oil at a ratio higher than $50 \mathrm{wt} \%$ would lead to the synthesis of BPF resin whose properties are governed by the less reactive bio-oil. Therefore, the large mass loss (41\%) for the $75 \%$ BPF resin at temperature ranges of 300 to $600{ }^{\circ} \mathrm{C}$ could be explained by the degradation of side chains present in the bio-oil molecules, and the breakdown of the methylene linkage, as was 
similarly observed by Wang et. al (2009). From Table 1, the residual carbon contents at $700{ }^{\circ} \mathrm{C}$ were 73,71 and 68 , 65, 42 \% for the commercial PF; laboratory synthesized pure PF and $25 \mathrm{wt} \% \mathrm{BPF}, 50 \mathrm{wt} \% \mathrm{BPF}, 75 \mathrm{wt} \% \mathrm{BPF}$ resins, respectively. The decrease in the carbon residue for BPF resins at an increased bio-oil ratio was due to the loss of numerous side chains from the bio-oil molecules (Wang et al., 2009). BPF resins with up to $50 \mathrm{wt} \%$ bio-oil displayed comparable thermal resistance to the pure PF resole resin

\section{Conclusions}

The thermal stability and thermal degradation kinetics of the PF resins were significantly affected by the resin synthesis conditions. The inclusion of the bark phenolic compound in the PF resin synthesis affected the thermal degradation and overall mass loss of the resin at 75wt\%

\section{Acknowledgement}

My profound appreciation goes to Professor O. Fasina for granting me short term scholar award to Auburn University for my Laboratory Research work. I will also like to thank Dr. Yusuf Celilbag for his Laboratory assistance and Via Brain, for allowing me access to his Laboratory both from the Department of Forest Product Auburn University, Alabama U.S.A. My utmost gratitude to Forestry Research Institute of Nigeria and Federal University of Technology Akure

\section{References}

i. Cetin, N. S and Ozmen, N. (2002): Use of organosolv lignin in phenol-formaldehyde resins for particleboard production -I. Organosolv lignin modified resins. International Journal of Adhesives. 22: 477-480.

ii. Cetin, N. S and Ozmen, N. (2002): Use of organosolv lignin in phenol-formaldehyde resins for particleboard production - II. Particleboard production and properties. International Journal of Adhesives22: 481-48

iii. Cheng, S., (2011): Bio-based phenolic resins and adhesives derived from forestry residues/ wastes and lignin. PhD Thesis, Lakehead University. Pp 77-155.

iv. Cheng, S; D`Cruz, I; Yuan, Z; Wang, M; Anderson, M; Leitch, M and Xu C. (2011): Using bio-crude derived from woody biomass to substitute for phenol at a high substitution level for production of bio-based phenolic resol resins. Journal of Applied Polymer Science.121: 2743- 2751.

v. Chetan, M. S; Ghadage, R. S; Rajan, C. R; Gunjikar, V. G and Ponrathnam, S. (1993): Thermolysis of orthonovolacs. Part 1. Phenol-formaldehyde and m-cresol formaldehyde resins, Thermochimica Acta, 228: 261-270.

vi. Gabilondo, N; López, M; Ramos, J. A; Echeverraí, J. M and Mondragon, I. (2007): Curing kinetics of amine and sodium hydroxide catalyzed phenol-formaldehyde resins. Journal of Thermochemical Analytical Calorimetry. 90(1): 229-236.

vii. Gardziella, A; Pilato, L and Knop, A. (2000):Phenolic resins: Chemistry, applications, standardization, safety, and ecology. (Springer Verlag).

viii. Khan, M. A and Ashraf, S. M. (2007): Studies on thermal characterization of lignin-Substituted phenol formaldehyde

ix. Kleinert, Mand Barth, T. (2008): Phenols form lignin, Chemical Engineering Technology. 31: 736-745.

x. Lee, S. H, and Ohkita, T. (2003): Rapid wood liquefaction by supercritical phenol. Wood Science Technology.37: 29-38.

xi. Ogunwusi, A. A. (2013): "Variation in the percentges of bark of ten tropical hardwood specie grown in Nigeria," Journal of life sciences ant Technology; Vol 7: 224-7181(Paper), ISSN 225-062x (online

xii. Órfão, J. J. M; and Martins, F. G. (2002): Kinetic analysis of thermogravimetric data obtained under linear temperature programming - A method based on calculations of the temperature integral by interpolation, Thermochimica Acta, 390:195-211

xiii. Park, B; Riedl, B; Hsu, E. W; and Shields. J. (1999): Differential Scanning Calorimetry of phenol-formaldehyde resins cure-accelerated by carbonates. Polymer40(7): 1689- 1699.

xiv. Russell, J. A and Riemath, W.F. (1985): Method for making adhesive from biomass. US Patent 4508 886, USA as represented by the United States Department of Energy.

xv. Shulman, G. P; and Lochte, H. W. (1996): Thermal degradation of polymers. -mass spectrometric thermal analysis of phenol-formaldehyde polycondensates. Journal of applied polymer science,10: 619-635.

xvi. Siddiqui, H. (2013): Production of lignin-based phenolic resin using de-polymerized kraft lignin and process optimization. Master's Thesis. The University of Western Ontario. London, Ontario, Canada.

xvii. Vázquez, G; González-Álvarez, J; López-Suevos, F; Freire, S and Antorrena, G. (2002): Curing kinetics of tannin phenol-formaldehyde adhesives as determined by DSC. Journal Thermochemical Analytical Calorimetry. 70 (1): 19-28.

xviii. Vyazovkin, S. (2001): Modification of the integral isoconversional method to account for variation in the activation energy, Journal of computational chemistry, 22:178-183. (2001) 
xix. Wang, M; Leitch, M and Xu, C. (2009): Synthesis of phenol-formaldehyde resol resins using organosolv pine lignins. Euroupean Polymer Journal, 12(45): 3380-3388.

xx. Zhao, Y; Yan, N and Feng, M. (2010): Characterization of phenol-formaldehyde resins derived from liquefied lodgepole pine barks. International journal of adhesion and adhesives. 